\title{
Effectiveness of Health Education Video in Improving Treatment Adherence among Patients with Tuberculosis: An Interventional Study from Bengaluru, India
}

\author{
Kruthika Nagaraj ${ }^{*}$, Renuka Prithviraj2, Rashmi M. Ramesh ${ }^{3}$, Rajappa Maheswaran², \\ Somashekar Narasimhaiah ${ }^{4}$, Kibballi Madhukeshwar Akshaya ${ }^{5}$ \\ ${ }^{1}$ Indegene Private Limited, Bengaluru, India \\ ${ }^{2}$ Sapthagiri Institute of Medical Sciences and Research Centre, Bengaluru, India \\ ${ }^{3}$ Philips India Private Limited, Bengaluru, India \\ ${ }^{4}$ National Tuberculosis Institute, Bengaluru, India \\ ${ }^{5}$ Yenepoya Medical College, Yenepoya (Deemed to Be University), Mangaluru, India \\ Email: ^kruthika.gowda1@gmail.com
}

How to cite this paper: Nagaraj, K., Prithviraj, R., Ramesh, R.M., Maheswaran, R., Narasimhaiah, S. and Akshaya, K.M. (2019) Effectiveness of Health Education Video in Improving Treatment Adherence among Patients with Tuberculosis: An Interventional Study from Bengaluru, India. Journal of Tuberculosis Research, 7, 159-169. https://doi.org/10.4236/jtr.2019.73016

Received: July 29, 2019

Accepted: September 26, 2019

Published: September 29, 2019

Copyright $\odot 2019$ by author(s) and Scientific Research Publishing Inc. This work is licensed under the Creative Commons Attribution International License (CC BY 4.0).

http://creativecommons.org/licenses/by/4.0/

(c) (i) Open Access

\begin{abstract}
Background: Non-adherence to tuberculosis (TB) treatment might prolong disease transmission and also increases the risk of drug resistance. Various studies have been carried out to determine the predictors of non-adherence but intervention-based studies to address treatment adherence are scarce. This study intends to estimate the treatment adherence rates following delivery of patient-centered health education videos in the intervention tuberculosis unit (TU) and to compare the treatment adherence with that in the comparison TU. Methods: An interventional study was conducted in two TUs of Bengaluru urban district among all newly diagnosed TB cases on daily regimen treatment over a period of three months from November 2017 to January 2018. A patient centered health education video was developed and shown by the treatment supporters to all eligible participants consenting to participate in the intervention TU. The video was shown once at the beginning of intensive phase treatment and once in the continuation phase of treatment. A total of 100 patients, 21 from intervention TU and 79 from comparison TU formed the study sample. Patient details were obtained from their treatment cards. Data on missed doses per month per patient were also noted. Data were entered into Microsoft excel worksheet and analyzed using statistical package for social sciences. Data are expressed as frequency and percentages. Chi-square test was applied to compare groups. Results: The majority of the study participants were aged between 25 - 44 years. Equal dis-
\end{abstract}


tribution of cases was seen among males and females. Intervention TU had significantly higher number of pulmonary TB cases. Treatment adherence rates were $90.5 \%$ and $84.8 \%$ at end of intensive phase and $85 \%$ and $71.4 \%$ at end of continuation phase in the intervention and comparison TU respectively, and this difference was not statistically significant. Conclusion: Use of mobile video-based health education showed better treatment rates and was found to improve TB treatment adherence.

\section{Keywords}

Health Education, Intervention, Treatment Adherence, Tuberculosis, Daily Dot

\section{Introduction}

Globally, the incidence of Tuberculosis (TB) in 2016 was 10.4 million. The incidence of TB in India was around 2,800,000, accounting to about a quarter of the world's TB cases, as per the Global TB report 2017 [1]. Poor treatment adherence increases the risk of drug resistance, treatment failures, relapses, deaths and prolonged infectiousness, and thus remains a hurdle to the success of TB programme [2]. Previous studies from India have shown factors, such as: instances of missed doses, side effects to anti-TB drugs, no support from health staff, inadequate knowledge of TB, alcoholism, inadequate patient-provider interaction, dissatisfied with services, improvement in symptoms and lack of time, lack of awareness about the duration of treatment and importance of full treatment and illiteracy [2] [3], to be associated with lost to follow up.

The directly observed treatment short-course strategy (DOTS) adopted under Revised National Tuberculosis control program (RNTCP) for TB control in India, has increased success rate of the coverage as well as disease cure rate, and yet lost to follow up continues to occur. Patients need to be educated properly to overcome problems during the treatment [4]. Case detection, addressing treatment gaps and development and implementation of new tools, may facilitate reduction of TB burden [5].

The use of mobile and wireless technologies to support the achievement of health objectives has the potential to transform the face of health service delivery across the globe [6]. Mobile Health (mHealth) has a crucial role to play in health care systems, as it can improve communication and enhance the integration of health care processes. A study carried out in India using a mHealth application for TB referrals has shown it to be highly effective [7]. In the present study, a mobile-based patient-centered health education video was developed, to be delivered to newly diagnosed TB patients on daily regimen anti-tuberculosis treatment (ATT), to assess its effectiveness in improving adherence to treatment under RNTCP.

Objectives: Among the newly diagnosed tuberculosis patients registered in 
two tuberculosis units (TUs) of Bengaluru urban district between November 2017 and January 2018:

1) To estimate the treatment adherence following delivery of "patient centered health education videos" in the intervention TU.

2) To compare the treatment adherence in the intervention $T U$ with that of the comparison TU.

\section{Methods}

\section{Study design:}

An interventional study was conducted in two TUs under Bengaluru urban district, Karnataka, India.

\section{Study setting:}

General setting: Bengaluru, the capital city of south Indian state of Karnataka, is a metropolitan city with a population of $9,621,551$ [8]. It is broadly sub-divided into three TB reporting units, as Bengaluru urban, Bengaluru rural and Bruhat Bengaluru Mahanagara Palike (BBMP). Each of these TB reporting areas provides $\mathrm{TB}$ care through a network of TUs, designated microscopy centers (DMCs), peripheral health institutions (PHIs) and directly observed treatment (DOT) center. Services for TB care have been integrated into general health care system and all the TB related services are provided free of cost.

Tuberculosis units (TUs): Bengaluru urban district has ten TUs catering to a population of 2,382,816. For the current study, two TUs were selected. TU attached to the medical college where the principal investigator was employed during the study initiation was taken as intervention TU and a neighboring TU was taken as comparison TU, which caters to populations of 215,302 and 215,304 respectively. The two TUs have three DMCs each with seven PHIs in intervention TU and eleven in comparison TU. In Karnataka, from November 2017 all TB patients were started on daily regimen treatment.

\section{Study population:}

All newly diagnosed adult TB patients; started on daily regimen treatment as per RNTCP guidelines in the study TUs, from November 2017 to January 2018 and consent to participate, constituted the study sample. Seriously ill TB patients and HIV-TB co-infected patients were excluded from the study (Figure 1).

\section{Sample size:}

All newly diagnosed TB patients during the study period, in both the TUs were considered as the study sample. Twenty-one (21) patients from intervention TU and 79 patients from comparison TU, adding to a total of 100 patients constituted the study sample.

\section{Process:}

An audio-visual health education video of 6.22 minutes duration containing details about common symptoms of TB, availability of diagnostic and treatment facility (treatment duration, frequency of drug administration, importance of completing the treatment course, side effects and its management, ill effects of 


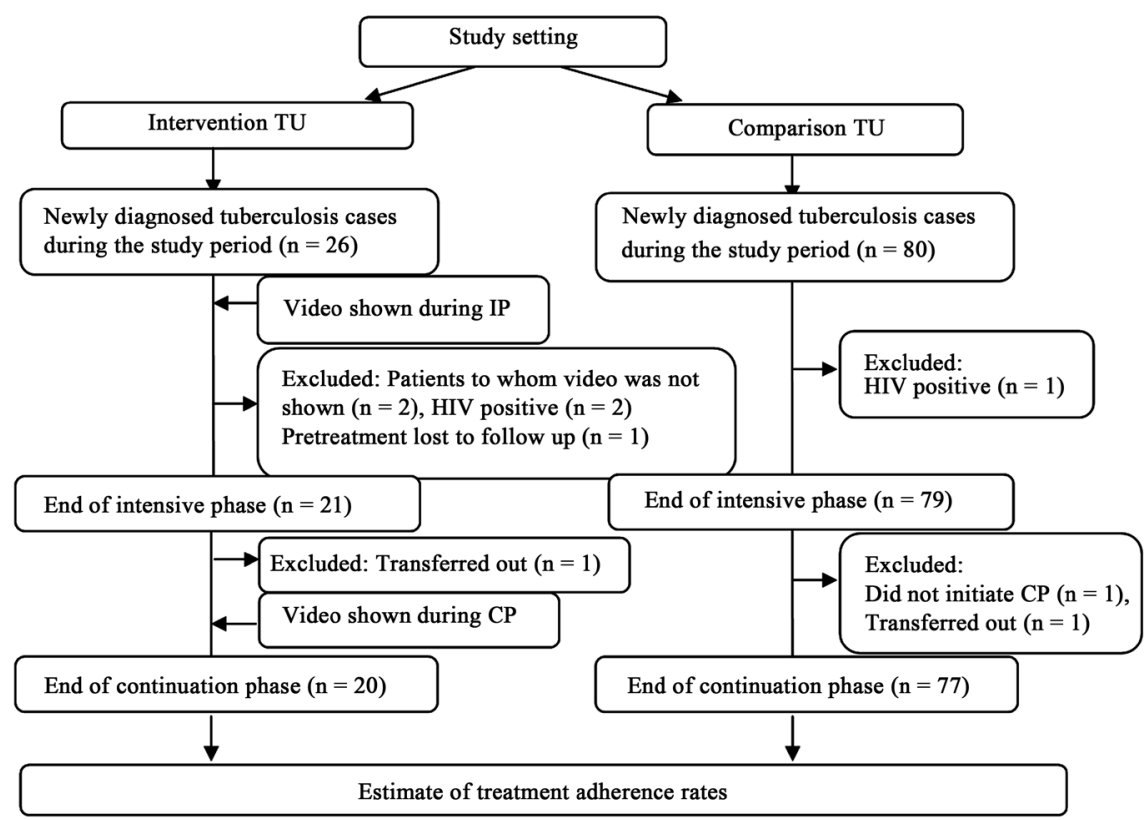

Figure 1. Conceptual framework of patient recruitment and intervention. $\mathrm{CP}=$ Continuous Phase; HIV = Human Immunodeficiency Virus; IP = Intensive Phase; TU = Tuberculosis Unit.

non-adherence to TB treatment and risk of drug resistance) was developed in Kannada (local language) by the research investigators and peer-reviewed for content and context validity. The video could be played on android based smart phones. The conceptual framework of the study has been presented in Figure 1.

In all the seven PHIs under the intervention TU, accredited social health activists (ASHAs) and pharmacists were acting as treatment supporters for the majority of TB cases. With the support of medical officers and senior treatment supervisor, we trained 92 ASHAs \& seven pharmacists in the intervention TU in their respective PHIs. Apart from the routine patient counselling, they were trained to deliver the health education video to the new TB patients diagnosed during the study period, once at the beginning of intensive phase (IP) by pharmacist and once at the beginning of continuation phase (CP) by the treatment supporter. Treatment supporters who did not have a suitable smart phone to play the video were excluded.

\section{Data collection variables and source of data:}

Information regarding the delivery of health education video to the TB patients was obtained by random telephonic conversation with the patients by the research investigators. Details of new TB patients started on treatment during the study period were obtained from the health worker of concerned PHIs. The patient details from both intervention and comparison $\mathrm{TU}$, including the socio-demographic variables, site of disease, sputum examination result and treatment-related details in terms number of missed doses per month was extracted from the patient treatment card into the abstraction form by the investigators.

\section{Definitions:}


World Health Organization defines drug adherence as the extent to which the patient's history of therapeutic drug-taking coincides with the prescribed treatment [9].

The operational definition of drug adherence for this study has been considered as the patient taking all the seven doses of treatment during a week and completing treatment of intensive phase by 56 days and continuation phase by 112 days as prescribed under daily regimen.

\section{Human subject protection:}

Informed consent was obtained from all the participants. Anonymity and confidentiality were maintained for the patient details obtained from treatment cards. Permission was obtained from District TB officer, Bengaluru urban district, to conduct the study in the selected TUs. The study was conducted after obtaining approval from the institutional ethics committee, Sapthagiri Institute of Medical Sciences \& Research Center, Bengaluru (IEC No: SIMS \& RC/IECC/ 04/2017, dated: 12.05.2017).

\section{Data entry and analysis:}

Data were entered into Microsoft Excel worksheet and were analyzed using statistical package for Social Sciences v.20. Descriptive statistics were expressed as frequencies and percentages. Chi-square/Fischer's exact test was applied to compare variables between groups. Mann-Whitney $U$ test was applied to compare differences in missed doses. Statistical tests were carried out at $5 \%(\mathrm{p}<$ 0.05) level of significance.

\section{Results}

The study recruited participants over a three month period and incorporated 21 cases from intervention TU and 79 from comparison TU. Patients from both TUs were comparable with respect to age and sex (Table 1). Socio-demographic and baseline characteristics of study subjects are presented in Table 1. The comparison TU had almost equal proportion of pulmonary and extra pulmonary $\mathrm{TB}$ cases, in contrast to intervention $\mathrm{TU}$ where pulmonary $\mathrm{TB}$ cases dominated with a significant difference $(P=0.02)$. A gap was observed in documentation of socio-demographic and baseline characteristics in the TB treatment cards.

Among the sputum positive TB patients, sputum conversion rate in intervention \& comparison TUs, at the end of IP of treatment was $87.5 \%$ and $92.7 \%$ respectively and by end of CP of treatment was $68.7 \%$ and $61 \%$ respectively. One (1) patient in intervention TU was identified to be sputum positive at the end of $\mathrm{CP}$ of treatment and on further investigation was diagnosed as multi-drug resistant TB. Among the sputum positive patients, the sputum results were not documented at the end of $\mathrm{CP}$ for $25 \%$ and $39 \%$ patients, in intervention and comparison TU's respectively. The documentation of sputum results in the TB cards of patients is presented in Table 2.

Non-adherence to TB treatment during IP was lower in the intervention TU with $2(9.5 \%)$ patients missing a dose, compared to $12(15.2 \%)$ patients from 
Table 1. Socio-demographic variables and baseline characteristics of study subjects.

\begin{tabular}{|c|c|c|c|c|c|c|}
\hline $\begin{array}{l}\text { Sl. } \\
\text { No }\end{array}$ & \multicolumn{2}{|c|}{ Socio-demographic variables } & $\begin{array}{c}\text { Intervention } \\
\quad \mathrm{TU} \\
{[\mathrm{n}=21](\%)}\end{array}$ & $\begin{array}{c}\text { Comparison } \\
\text { TU } \\
{[\mathrm{n}=79](\%)}\end{array}$ & $\begin{array}{l}\text { Total } \\
\mathrm{N}(\%)\end{array}$ & P-value \\
\hline \multirow{6}{*}{1} & \multirow{6}{*}{ Age (years) } & $15-24$ & $4(19)$ & $15(19)$ & $19(19)$ & \multirow{6}{*}{-} \\
\hline & & $25-34$ & $6(28.6)$ & $20(25.3)$ & $26(26)$ & \\
\hline & & $35-44$ & $5(23.8)$ & $21(26.6)$ & $26(26)$ & \\
\hline & & $45-54$ & 0 & $14(17.7)$ & $14914)$ & \\
\hline & & $55-64$ & $3(14.3)$ & $8(10.1)$ & $11(11)$ & \\
\hline & & $\geq 65$ & $3(14.3)$ & $1(1.3)$ & $4(4)$ & \\
\hline \multirow{2}{*}{2} & \multirow{2}{*}{ Sex } & Male & $12(57.1)$ & $47(59.5)$ & $59(59)$ & \multirow{2}{*}{0.84} \\
\hline & & Female & $9(42.9)$ & $32(40.5)$ & $41(41)$ & \\
\hline \multirow{4}{*}{3} & \multirow{4}{*}{$\begin{array}{c}\text { Current } \\
\text { employment } \\
\text { status }\end{array}$} & Employed & $10(47.6)$ & $36(45.6)$ & $46(46)$ & \multirow{4}{*}{0.003} \\
\hline & & Not employed & $8(38.1)$ & $8(10.1)$ & $16(16)$ & \\
\hline & & Home maker & $3(14.3)$ & $15(19)$ & $18(18)$ & \\
\hline & & Not documented & 0 & $20(25.3)$ & $20(20)$ & \\
\hline \multirow{3}{*}{4} & \multirow{3}{*}{$\begin{array}{l}\text { Socio-economic } \\
\text { class }\end{array}$} & Above Poverty Line & $5(23.8)$ & $7(8.9)$ & $12(12)$ & \multirow{3}{*}{0.01} \\
\hline & & Below Poverty Line & $11(52.4)$ & $26(32.9)$ & $37(37)$ & \\
\hline & & Not documented & $5(23.8)$ & $46(58.2)$ & $51(51)$ & \\
\hline \multirow{2}{*}{5} & \multirow{2}{*}{ Site of disease } & Pulmonary & $17(81)$ & $43(54.4)$ & $60(60)$ & \multirow{2}{*}{0.02} \\
\hline & & Extra-pulmonary & $4(19)$ & $36(45.6)$ & $40(40)$ & \\
\hline \multirow{3}{*}{6} & \multirow{3}{*}{ Case definition } & $\begin{array}{l}\text { Microbiologically } \\
\text { confirmed }\end{array}$ & $16(76.2)$ & $44(55.7)$ & $60(60)$ & \multirow{3}{*}{0.22} \\
\hline & & Clinically diagnosed & $5(23.8)$ & $34(43)$ & $39(39)$ & \\
\hline & & Not specified & 0 & $1(1.3)$ & $1(1)$ & \\
\hline \multirow[b]{2}{*}{7} & \multirow[b]{2}{*}{ HIV status } & Non-reactive & $21(100)$ & $74(93.7)$ & $95(95)$ & \multirow[b]{2}{*}{$0.29^{\star}$} \\
\hline & & $\begin{array}{c}\text { Unknown/ } \\
\text { Not documented }\end{array}$ & 0 & $5(6.3)$ & $5(5)$ & \\
\hline \multirow{3}{*}{8} & \multirow{3}{*}{ Diabetes status } & Diabetic & $3(14.3)$ & $13(16.5)$ & $16(16)$ & \multirow{3}{*}{-} \\
\hline & & Non-diabetic & $18(85.7)$ & $60(75.9)$ & $78(78)$ & \\
\hline & & Not documented & 0 & $6(7.6)$ & $6(6)$ & \\
\hline \multirow{4}{*}{9} & & ASHA & $19(90.5)$ & $33(41.8)$ & $52(52)$ & \\
\hline & Treatment & Pharmacist & 0 & $3(3.8)$ & $3(3)$ & \\
\hline & & Other s & $2(9.5)$ & $38(48.1)$ & $40(40)$ & \\
\hline & & Not documented & 0 & $5(6.3)$ & $5(5)$ & \\
\hline & & Yes & $2(9.5)$ & $7(8.9)$ & $9(9)$ & \\
\hline 10 & $\begin{array}{l}\text { Current } \\
\text { smoker }\end{array}$ & No & $17(81)$ & $45(57)$ & $62(62)$ & 0.08 \\
\hline & & Not documented & $2(9.5)$ & $27(34.2)$ & $29(29)$ & \\
\hline & & Yes & 0 & $1(1.3)$ & $1(1)$ & \\
\hline 11 & $\begin{array}{l}\text { Current chewable } \\
\text { tobacco user }\end{array}$ & No & $19(90.5)$ & $49(62)$ & $68(68)$ & 0.04 \\
\hline & & Not documented & $2(9.5)$ & $29(36.7)$ & $31(31)$ & \\
\hline & & Yes & $1(4.8)$ & $7(8.9)$ & $8(8)$ & \\
\hline 12 & $\begin{array}{c}\text { Current } \\
\text { alcohol user }\end{array}$ & No & $17(81)$ & $41(51.9)$ & $58(58)$ & 0.05 \\
\hline & & Not documented & $3(14.3)$ & $31(39.2)$ & $34(34)$ & \\
\hline
\end{tabular}

ASHA: Accredited Social Health Activist; HIV: Human Immunodeficiency Virus. 
Table 2. Sputum conversion rate among the sputum positive tuberculosis patients.

\begin{tabular}{|c|c|c|}
\hline Sputum results & $\begin{array}{l}\text { Intervention TU } \\
\qquad \mathrm{N}=16\end{array}$ & $\begin{array}{l}\text { Comparison TU } \\
\qquad \mathrm{N}=41\end{array}$ \\
\hline $\begin{array}{l}\text { Sputum conversion at end of IP; } \\
\text { No. of sputum negative patients/Total sputum positive patients before treatment initiation }\end{array}$ & $15 / 16(87.5 \%)$ & $38 / 41(92.7 \%)$ \\
\hline $\begin{array}{l}\text { Sputum conversion at end of CP (cured); } \\
\text { No. of sputum negative patients/Total sputum positive patients before treatment initiation }\end{array}$ & $11 / 16(68.7 \%)$ & $25 / 41(61 \%)$ \\
\hline $\begin{array}{l}\text { Sputum positive at end of } \mathrm{CP} \text { (treatment failure); } \\
\text { No. of sputum positive patients at end of CP/Total sputum positive patients before treatment initiation }\end{array}$ & $1 / 16(6.3 \%)$ & -- \\
\hline Not documented at end of CP & $4 / 16(25 \%)$ & $16 / 41(39 \%)$ \\
\hline
\end{tabular}

$\mathrm{CP}=$ continuation phase; $\mathrm{IP}=$ intensive phase; $\mathrm{N}$ = sputum positive pulmonary $\mathrm{TB}$ patients before treatment initiation; $\mathrm{TU}=$ tuberculosis unit.

comparison TU. Similarly, during CP of treatment, 3 (15\%) patients from intervention TU and $22(28.6 \%)$ patients from comparison TU had missed doses. Adherence to TB treatment was better in the intervention TU than in the comparison TU. However, these differences were not found to be statistically significant (Table 3). The number of extra days taken to complete missed doses by the non-adherent cases is presented in Table 3.

There was no association of any socio-demographic variables with the TB treatment adherence in both the TUs ( $p>0.05)$. The association between TB treatment adherence and addictions could not be estimated due to non-documentation of data for most of the patients. Almost $90 \%$ patients each, in both intervention and comparison TU had successful TB treatment outcomes (cured or treatment completed). Around 5\% patients in comparison TU were lost to follow up and one patient in intervention TU was diagnosed as multi-drug resistant TB. The treatment outcomes at the end of the study are presented in Figure 2.

\section{Discussion}

This was one of the few studies from the Indian context which looked into of digital technology using a health education video to improve treatment adherence among patients under RNTCP.

The advocacy communication and social mobilization activities under RNTCP works towards improving TB control by promoting positive behavior change among people regarding $\mathrm{TB}$ and empowering communities to change. Thus for a behavior change communication to be effective, it needs to convey to people more than just the medical facts [10]. Studies have also shown multitude of factors influencing the drug adherence pattern in $\mathrm{TB}$ and one of them being the emphasis to improve the interpersonal communication skills between the patient and healthcare providers [3] [11]. In today's world, it has been made easier with use of mobile and software technology, one such initiative is pilot tested hereby using a video-based communication to assess the impact on treatment-related behavior in TB patients. 
Table 3. Details on treatment adherence and retrieval action for missed doses among study subjects.

\begin{tabular}{|c|c|c|c|c|c|c|}
\hline S1. No. & Treatment adherence & & $\begin{array}{c}\text { Intervention TU } \\
\mathrm{N}=21(\%)\end{array}$ & $\begin{array}{l}\text { Comparison TU } \\
\mathrm{N}=79(\%)\end{array}$ & Total & P-value \\
\hline \multirow{2}{*}{1} & Adherent to & No & $2(9.5)$ & $12(15.2)$ & $14(14)$ & \multirow{2}{*}{0.5} \\
\hline & treatment during IP & Yes & $19(90.5)$ & $67(84.8)$ & $86(86)$ & \\
\hline \multirow{2}{*}{2} & \multirow{2}{*}{$\begin{array}{l}\text { Documentation of retrieval action } \\
\text { for doses missed during IP }\end{array}$} & No & $1(50)$ & $9(75)$ & $10(71.4)$ & \multirow{2}{*}{$0.5^{*}$} \\
\hline & & Yes & $1(50)$ & $3(25)$ & $4(28.6)$ & \\
\hline 3 & $\begin{array}{c}\text { Doses missed during IP; } \\
\text { median (IQR)/(minimum - maximum) }\end{array}$ & & $1(1-1) /(1)$ & $2(1-27) /(1-54)$ & - & 0.05 \\
\hline \multirow[b]{2}{*}{4} & \multirow{2}{*}{ Adherent to treatment during $\mathrm{CP}$} & No & $3(15)$ & $22(28.6)$ & $25(25.8)$ & \multirow{2}{*}{0.2} \\
\hline & & Yes & $17(85)$ & $55(71.4)$ & & \\
\hline \multirow{2}{*}{5} & \multirow{2}{*}{$\begin{array}{l}\text { Documentation of retrieval } \\
\text { action for doses missed during CP }\end{array}$} & No & $2(66.7)$ & $19(86.4)$ & $21(84)$ & \multirow{2}{*}{$0.42^{*}$} \\
\hline & & Yes & $1(33.3)$ & $3(13.6)$ & $4(16)$ & \\
\hline 6 & $\begin{array}{c}\text { Doses missed during } \mathrm{CP} \\
\text { median }(\mathrm{IQR}) /(\text { minimum - maximum })\end{array}$ & & $2 /(2-30)$ & $6(3-17.25) /(1-99)$ & - & 0.69 \\
\hline
\end{tabular}

Note: ${ }^{\star}$ Fischer's exact test. $\mathrm{CP}=$ continuation phase; $\mathrm{IP}=$ intensive phase; $\mathrm{IQR}=$ interquartile range; $\mathrm{TU}=$ tuberculosis unit.

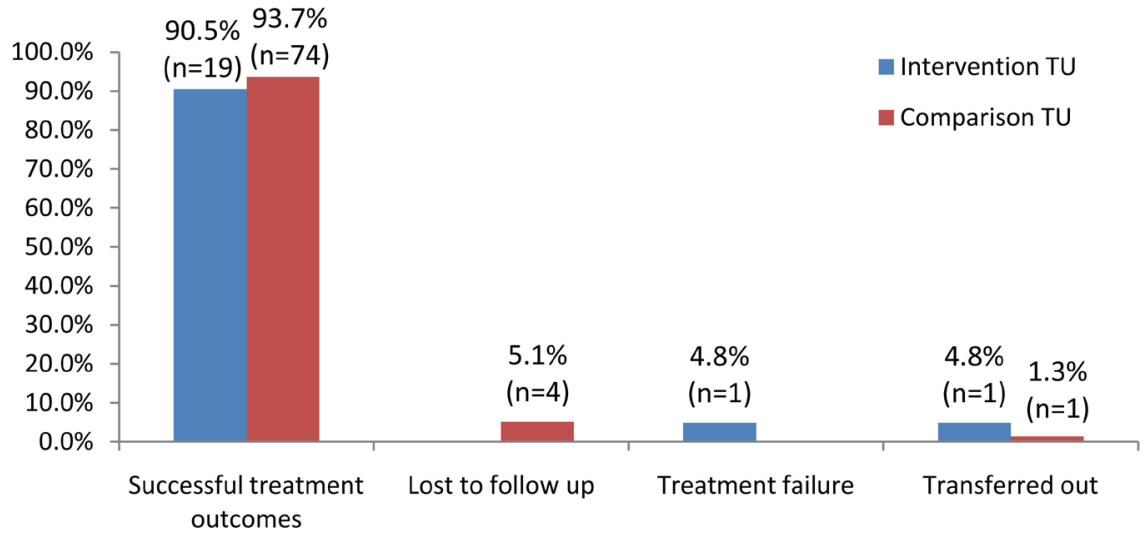

Figure 2. Tuberculosis treatment outcome among the study participants.

In the present study, the majority (52\%) of patients were between 25 to 44 years, the productive age group in any community indicating economic impact both at household and at the national level. There is almost equal distribution of disease in both the sexes, probably because of gradually increasing awareness levels and changing scenario in society regarding attitude towards women's health. In a study by Mittal et al. [3], similar representation of patients in the productive age group was noted and the majority patients were males (61.3\%). Further, there appears to be gaps in documenting information regarding occupation, socioeconomic status and addiction-related information, the importance of which could be reinforced in the ensuing meetings by the concerned officials.

The use of patient-centered health education video in the present study to reduce missed doses and thus improve TB treatment adherence showed better adherence rates in intervention TU than in the comparison TU. However, signifi- 
cant differences could not be established.

Literature on use of mobile video-based intervention to improve TB treatment adherence in India is scarce. A study carried in Pune, using photo voice video showed three times significantly higher odds of successful TB treatment outcomes in the intervention group than in the comparison group [12]. Another study carried out in Karnataka, to determine the effect of intensive health education on adherence to treatment in sputum positive pulmonary TB patients, there was no significant association between intensive health education and adherence to treatment. Also, adherence to treatment was not associated with any socio-demographic variables such as age, sex, education, economic status and family support received [13]. Another study carried out in Bangladesh using physician provided patient education to improve TB treatment adherence, showed a significantly greater cumulative adherence to anti-tuberculosis medication in the intervention group than in the control group [11]. While a study from Ethiopia, tried psychological and educational intervention to improve TB treatment adherence and found a significant difference with regard to non-adherence level between intervention and control groups [14].

With lower rate of non-adherence to ATT in intervention TU, our experience extends the results of above studies which have shown positive effects of health education video. Therefore, studies with large sample size could be carried out to demonstrate for effectiveness of this intervention and its impact on treatment adherence on long term.

Use of interventions such as health education video could be integrated into RNTCP to further improve adherence rates to ATT. In order to improve the overall standards of maternal and child health service provision in India and related data collection, with support from United Nations Children's Fund (UNICEF), the ministry of health and family welfare, Government of India, has introduced an android based tablet-based application ANMOL (Auxiliary Nurse Midwives Online) [15]. The use of android based tabs by health care providers to update information related to various national programmes also provides an opportunity to incorporate such educational videos, to be used when required. Their use can also be explored for other diseases.

Strengths of the study are that it is one of the few studies conducted in India using mobile-based health education video to enhance TB treatment adherence. The video was developed in local language, making it easier for patients to understand. Health education using a video affects both cognitive and affective domain of an individual enabling better understanding. As the study involved program staff (treatment supporters) to deliver the video, it could be a feasible intervention, if considered into the program. The study followed CONSORT guidelines.

The study had limitations of having a small sample in the intervention TU to arrive at a conclusion on the effectiveness of the intervention studied. Also, requirement of a smart phone to play the video and involvement of treatment supporters to deliver the video to the patients were the challenges. Acceptance 
by the patients to watch the video was also an important challenge observed during the study.

\section{Conclusion}

Our study using video-based health education showed better treatment adherence with less non-adherence rates in intervention TU compared to the comparison TU. New technology-based interventions could be introduced into the programme to make delivery of health education more effective and improve TB treatment adherence.

\section{Acknowledgements}

This project was undertaken as part of the "Operational Research for Medical College Faculty under RNTCP” conducted by RNTCP State Task Force Operational Research Committee, Karnataka with the funding support from The State Tuberculosis Office, Bengaluru; Government of Karnataka. The project and manuscript were developed during the "protocol development" and "scientific paper writing" workshops respectively. We acknowledge the facilitation of the study by District TB Officer (Bengaluru Urban). We express our heartfelt gratitude to the dean and faculty of department of Community Medicine, Sapthagiri Institute of Medical Sciences and Research Centre, Bengaluru; all the Medical Officers of Primary Health Centre's and the RNTCP staff of Bengaluru urban district for their unconditional support during the conduct of the study.

\section{Conflicts of Interest}

The authors declare no conflicts of interest regarding the publication of this paper.

\section{Author's Contribution}

Conceived \& designed: RMR, KN, RV, SN, AKM; Performed the experiment: $\mathrm{KN}, \mathrm{RV}$; Analyzed the data: KN, RV; Wrote the paper: KN, RV; Provided comments \& inputs to revise manuscript: RMR, KN, RV, RM, SN, AKM.

\section{Disclaimer}

The authors are responsible for the views expressed in this publication. They do not represent the decisions of RNTCP State Task Force Operational Research Committee, Karnataka or the RNTCP State TB Office, Karnataka.

\section{References}

[1] Central TB Division (2018) India TB Report 2018. Revised National TB Control Programme. Annual Status Report. Directorate General of Health Services, Ministry of Health and Family Welfare, New Delhi. https://tbcindia.gov.in/showfile.php?lid = 3314

[2] Vijay, S., Kumar, P., Chauhan, L.S., Vollepore, B.H. and Kizhakkethil, U.P. (2010) Risk Factors Associated with Default among New Smear Positive TB Patients 
Treated Under DOTS in India. PLoS ONE, 5, e10043. https://doi.org/10.1371/journal.pone.0010043

[3] Mittal, C. and Gupta, S.C. (2011) Noncompliance to DOTS: How It Can Be Decreased. Indian Journal of Community Medicine, 36, 27-30. https://doi.org/10.4103/0970-0218.80789

[4] Basa, S. and Venkatesh, S. (2015) Study on Default and Its Factors Associated among Tuberculosis Patients Treated under DOTS in Mayurbhanj District, Odisha. Journal of Health Research and Reviews, 2, 25-28. https://doi.org/10.4103/2394-2010.158125

[5] World Health Organization (2015) Global Tuberculosis Report 2015. 20th Edition. https://apps.who.int/iris/bitstream/handle/10665/191102/9789241565059_eng.pdf?s equence $=1$ \&isAllowed $=\mathrm{y}$

[6] World Health Organization (2011) mHealth: New Horizons for Health through Mobile Technologies. Geneva, Switzerland.

https://www.who.int/goe/publications/goe_mhealth_web.pdf

[7] Chadha, S., Trivedi, A., Nagaraja, S.B. and Sagili, K. (2017)Using mHealth to Enhance TB Referrals in a Tribal District of India. Public Health Action, 7, 123-126. https://doi.org/10.5588/pha.16.0080

[8] Census of India 2011 (2014) District Census Handbook Bangalore. Directorate of Census Operations, Karnataka. Government of India. http://censusindia.gov.in/2011census/dchb/2918_PART_B_DCHB_BANGALORE. pdf

[9] World Health Organization (2003) Adherence to Long-Term Therapies-Evidence for Action. http://apps.who.int/medicinedocs/en/d/Js4883e/8.9.1.html

[10] World Health Organization (2007) Advocacy, Communication and Social Mobilization for Tuberculosis Control: A Handbook for Country Programmes. Stop TB Partnership.

http://www.stoptb.org/assets/documents/resources/publications/acsm/acsm_handb ook.pdf

[11] Lee, S., Khan, O.F., Seo, J.H., Kim, D.Y., Park, K., Jung, S., et al. (2013) Impact of Physician's Education on Adherence to Tuberculosis Treatment for Patients of Low Socioeconomic Status in Bangladesh. Chonnam Medical Journal, 49, 27-30. https://doi.org/10.4068/cmj.2013.49.1.27

[12] Shelke, S.C., Adhav, P.S., Moonan, P.K., Willis, M., Parande, M.A., Satyanarayana, S., et al. (2014) Photovoice: A Novel Approach to Improving Antituberculosis Treatment Adherence in Pune, India. Tuberculosis Research and Treatment, 2014, Article ID: 302601. https://doi.org/10.1155/2014/302601

[13] D'Souza, J. (2003) Effect of Intensive Health Education on Adherence to Treatment in Sputum Positive Pulmonary Tuberculosis Patients. Indian Journal of Tuberculosis, 50, 33-38.

[14] Tola, H.H., Shojaeizadeh, D., Tol, A., Garmaroudi, G., Yekaninejad, M.S., Kebede, A., et al. (2016) Psychological and Educational Intervention to Improve Tuberculosis Treatment Adherence in Ethiopia Based on Health Belief Model: A Cluster Randomized Control Trial. PLoS ONE, 11, e0155147. https://doi.org/10.1371/journal.pone.0155147

[15] UNICEF, India. ANMOL-ANMs Online. http://unicef.in/Story/1183/ANMOL-ANMs-Online 